\section{LAS CIRCUNSCRIPCIONES ESPECIALES TRANSITORIAS DE PAZ, ¿UNA PROPUESTA PARA MEJORAR LA REPRESENTACIÓN POLÍTICA DE LOS SECTORES Y LAS REGIONES MÁS AFECTADAS POR EL CONFLICTO ARMADO INTERNO?*}

\author{
THE TEMPORARY SPECIAL CONSTITUENCIES \\ FOR PEACE: A PROPOSAL TO IMPROVE \\ POLITICAL REPRESENTATION OF THE \\ REGIONS AND SECTORS AFFECTED THE MOST \\ BY THE DOMESTIC ARMED CONFLICT?
}

\author{
AS CIRCUNSCRIÇÕES ESPECIAIS \\ TRANSITÓRIAS DE PAZ, UMA PROPOSTA PARA \\ MELHORAR A REPRESENTAÇÃO POLÍTICA \\ DOS SETORES E REGIÕES MÁIS AFETADOS \\ PELO CONFLITO ARMADO INTERNO?
} \author{
.
}


se cierne bajo el convencimiento de que la política en Colombia ha sido un elemento de la violencia y de que el conflicto armado tiene profundas causas políticas relacionadas con una democracia restringida, ilegitimidad en el sistema de partidos además de problemas de representación política.

\section{PALABRAS CLAVES}

Violencia política, Acuerdo de paz, participación política, reformas políticas, representación política, circunscripciones electorales de paz.

\section{ABSTRACT}

The peace deal in Colombia to end the conflict and to build a stable and lasting peace sets out in point 2 , in terms of political participation, a "democratic opening" agreement. This agreement seeks to promote democracy and participation among the groups of Colombian society, which have been historically excluded from political representation. In order to have autonomy and independence, the proposals of the agreement aim to strengthen citizen participation, to offer guarantees to the political opposition, and to reform the electoral organization. Those "democratic opening mechanisms" include the proposal of the special peace electoral constituencies for the House of Representatives, which hang over the conviction that politics in Colombia has been one of the perpetrators of violence, and that the armed conflict has been deeply rooted political causes related to a restricted democracy, illegitimacy in the party system as well as serious problems in terms of political representation.

\section{KEYWORDS}

Political violence, political reforms, peace deal, political participation, political representation, electoral constituencies of peace.

\section{RESUMO}

O Acordo final para o término do conflito e a construção de uma paz estável e duradoura, estabelece no segundo ponto, relacionado à participação política, um pacto de "abertura democrática" que busca o aprofundamento da democracia e a participação de setores que foram historicamente excluídos da representação política. As propostas deste Acordo estão localizadas em mecanismos para fortalecer a participação cidadã, oferecer garantias à oposição e reformar a organização eleitoral para permitir autonomia e independência.

Dentro desses mecanismos de "abertura democrática" está a proposta das Circunscrições Especiais Transitórias de Paz para a Câmara dos Deputados, que se sustenta no entendimento de que a política na Colômbia tem sido um elemento de violência e que o conflito armado está relacionado a uma democracia restrita, ilegitimidade no sistema partidário e problemas de representação política.

\section{PALAVRAS-CHAVE}

Violência política, acordo de paz, participação política, reformas políticas, representação política, Circunscrições Especiais de Paz.

\section{INTRODUCCIÓN}

El presente documento es producto de la revisión del tema: Circunscripciones transitorias especiales de paz, y el problema planteado parte del reconocimiento de que un elemento relacionado con el conflicto armado interno del país ha sido la falta de garantías de los derechos políticos de líderes y lideresas, así como agrupaciones políticas y sociales, que fueron sistemáticamente perseguidos $y$ asesinados por razón de su liderazgo político, lo cual llevo a un problema de subrepresentación de estos sectores y de las regiones afectados por el conflicto armado.

En ese orden, en el punto 2 del Acuerdo de La Habana se ha propuesto resolver tal subrepresentación de estos sectores y de los territorios afectados por el conflicto armado, así lo dispone cuando señala que la democracia requiere de un escenario de fin del conflicto y un fortalecimiento de las garantías de participación política. Tales garantías suponen medidas incluyentes que faciliten la participación política sobre todo de zonas apartadas o afectadas por el conflicto y el abandono, esto significa que en una fase de transición, estos territorios y sus poblaciones tengan una mayor representación en el Congreso. 
De ahí que se plantee la pregunta: ¿la creación de 16 circunscripciones transitorias especiales de paz para la Cámara de Representantes en los periodos constitucionales 2018-2022 y 2022 - 2026, contribuye a mejorar el problema de subrepresentación de algunos sectores afectados por la violencia y de territorios igualmente golpeados por el conflicto armado colombiano y el abandono?

Frente a lo anterior se plantea la hipótesis de que la propuesta de la Circunscripción electoral transitoria de paz contiene medidas tendientes a resolver el problema de la subrepresentación de sectores y regiones que fueron afectados por el conflicto armado interno.

Por ello el objetivo del documento es analizar el contenido de la propuesta de las Circunscripciones Especiales Transitorias de Paz (CETP) planteadas en el punto dos (2.3.6) del Acuerdo Final de Paz, a partir de tres aspectos:

i. Un contexto que justifica y explica la reforma política de las circunscripciones desde la historia de la violencia política $y$ el frente nacional, como se sabe una de las causas del conflicto armado así como sus consecuencias se encuentran en la violencia ejercida por razones políticas que ha significado la exclusión de sectores de la población, políticos y de algunos territorios. De igual forma el contexto implica estudiar los cambios y las reformas políticas acaecidas con la Constitución de 1991, así como las reformas políticas ocurridas posteriores a la Carta y llevadas a cabo con el fin de mejorar el sistema de partidos.

ii. La definición jurídica de circunscripción electoral en Colombia.

iii. La descripción del proceso de paz y en especial de la propuesta de las Circunscripciones electorales transitorias de paz hasta su desarrollo a la fecha (Agosto 28 de 2017).

Para abordar el desarrollo del siguiente trabajo se realiza una investigación teórica en la que se procede a la comprensión de conceptos sobre el ejercicio del derecho a la participación política desde el contexto colombiano marcado por la violencia política y del conflicto armado. El aporte que se busca desde esta investigación es la conceptualización, revisión y descripción del tema objeto de estudio y el planteamiento de propuestas al respecto.

\section{CONTEXTO}

\subsection{La violencia política y el frente nacional}

Después de más de un siglo de divisiones y nueve guerras civiles en el siglo XIX y tras la violencia entre los partidos políticos: liberal y conservador que dejó una lamentable cifra de 300.000 muertos entre 1946 y 1958, los dirigentes políticos nacionales acordaron derrocar al General Rojas Pinilla e instaurar un régimen de entendimiento.

En tal sentido Alberto Lleras Camargo, jefe en ese entonces del partido liberal, viajó hasta España para reunirse con Laureano Gómez con el fin de discutir una fórmula que permitiera entenderse, arreglo que consistió en que a partir de 1958 y por 16 años se repartirían los cargos públicos por mitad entre liberales y conservadores, y que los presidentes se alternarían el gobierno cada cuatro años, dicha fórmula se le llamo "Frente Nacional" (Tirado, 1982).

El frente nacional significó un esfuerzo por acabar los enfrentamientos entre los partidos liberal y conservador y por modernizar el Estado colombiano frente a una violencia política en los años cincuenta dada por: la redefinición del poder indirecto y como reacción al proceso de centralización política; a la articulación de una red política para el dominio del centro político sobre la región ; y como exigencia para que el Estado rompiera la mediación a través de los intermediarios tradicionales y contrario a ello, accediera directamente a la comunidad (González, Bolívar y Vásquez, 2009).

Pero si bien el régimen de responsabilidad compartida del Frente Nacional redujo los efectos de la violencia, lo cierto es que también se convirtió en un obstáculo para la modernización del aparato estatal, esto porque se limitó solamente a confrontar las manifestaciones políticas de la violencia, resolviendo el acceso al poder y el reparto de la burocracia gubernamental entre dos partidos internamente homogéneos, pero dejo de lado problemas que generaban violencia como enfrentamientos por 
tierras, luchas locales y sociales por acceso al trabajo o al comercio, la inconformidad de la ciudadanía frente a instituciones estatales como el Congreso de la República, Corporación criticada por la negligencia en el cumplimiento de sus funciones constitucionales y por constituir el símbolo de la decadencia de la clase política y de la corrupción (Konrad Adenauer Stiftung, 2011). Además es necesario indicar que si bien el Frente Nacional redujo significativamente la violencia entre los partidos tradicionales, no atendió una larga historia de conflictos sociales no resueltos con raíces en el pasado colonial (Medina, 2009, p. 162), concernientes con la distribución de la riqueza y la propiedad rural (p. 166) y sobre todo, al cerrar la participación política posibilitó la aparición y, en gran parte, la justificación de la aparición de varias guerrillas colombianas.

Entonces, el régimen del frente nacional dificultó la modernización de los partidos políticos y el no surgimiento de organizaciones políticas nuevas y modernas, conllevando a una crisis de la representación política que afectó a las instituciones del Estado y a las formas de mediación política en el ámbito social, asimismo implicó que lo político se identificara con la clase política tradicional lejana de los intereses sociales (González, et al, 2009).

\subsection{La violencia política en los años 80 y 90}

Entre los años de 1988 y 1991 se incrementaron los asesinatos a civiles en la mayoría de los casos dirigentes militantes y simpatizantes de la Unión Patriótica, miembros de sindicatos, de organizaciones populares e indígenas (Universidad Externado, 2009).

El 22 de marzo de 1990 fue asesinado Bernardo Jaramillo Ossa, líder de la Unión Patriótica, movimiento surgido del proceso de paz a mediados de los ochenta entre el gobierno de Belisario Betancurt y las Farc. Esta agrupación política (UP) en la contienda logró “(...) 19 alcaldías directamente y 95 en coalición con otros movimientos, 18 diputados y 368 concejales (...)" (Semana, 2015)

Por otra parte, tras la firma de los Acuerdos con el M-19 fue asesinado el máximo líder de esa organización, Carlos Pizarro Leóngómez, el 26 de abril de 1990, en medio del ejercicio de su campaña presidencial.
Con estos crímenes, entre otros, que llevo al genocidio político de la UP, se finalizaba la apertura política de los gobiernos de Belisario Betancur y Virgilio Barco, y ello cambió la historia, ya que a mediados de los años noventa sin UP ni M-19 como agrupaciones políticas consolidadas, la política es relegada y se intensifica la guerra por organizaciones ilegales como las Farc, la cual logra incrementar su accionar con secuestros, masacres, entre otros hechos victimizantes y delitos de lesa humanidad.

Violencia profundizada también por el accionar de otros actores al margen de la ley tales como las AUC, los cuales victimizaron y cometieron toda serie de crímenes y violaciones. Ambos grupos armados al margen de la ley violaron los derechos humanos de millones de ciudadanos colombianos por el control territorial y el poder político local.

Esta realidad llevo a contradecir el espíritu democrático y participativo de la Constitución de 1991, fundamentalmente por el hecho de coexistir elecciones democráticas y violencia armada de grupos irregulares, llevando a que en Colombia se viviera una "democracia incompleta" o "restringida" que en lugar de una participación activa de la ciudadanía en las decisiones políticas mantuvo "una versión cerrada y unilateral del poder político y financiero que se ha instalado en las tecnoestructuras dominantes en los últimos años" (Rodríguez Arana, 2014, p. 66)

\subsection{La Constitución de 1991 y las reformas políticas}

\subsubsection{La Constitución de 1991}

Como se mencionó previamente, los efectos del bipartidismo histórico fueron principalmente una crisis de representación política (Hernández, 2009), por lo que en la Constitución de 1991 se trató de corregir los problemas del sistema político además de equilibrar los poderes de las ramas del poder público.

Principalmente se buscó corregir al régimen bipartidista y para ello se adoptaron disposiciones que han permitido que la participación política se ejerza no solo desde partidos políticos, tales como la habilitación a las organizaciones ciudadanas para participar en contiendas, es así que en el artículo 40 constitucional se establece que "Todo ciudadano 
tiene derecho a constituir partidos, movimientos y agrupaciones políticas sin limitación alguna".

A su vez el artículo 107 constitucional señala que son actores organizados de la política: los partidos y movimientos políticos, y les garantiza a las organizaciones sociales el derecho a manifestarse y participar en eventos políticos.

De igual forma el artículo 108 de la Constitución establece que pueden conseguir personería jurídica reconocida por el Consejo Nacional Electoral (CNE), los partidos, movimientos políticos y grupos significativos de ciudadanos (Hernández, et al., 2009).

Sin embargo, la Constitución de 1991 con el fin de acabar con el bipartidismo incluyó medidas que llevaron al crecimiento desmedido del número de partidos políticos y a una excesiva personalización de la política (Puyana, 2012).

Tales inconvenientes se incrementaron con la falta de democracia interna de los partidos, liderazgo acumulativo y al ejercicio de oposición de terceras fuerzas, entre otros motivos.

Es así que muchas de las medidas adoptadas solo lograron limitar las prácticas tradicionales de los partidos pero no la de fomentar su modernización y organización democrática. Además, las propuestas de solo corregir las prácticas tradicionales de los partidos políticos se basaron en un análisis simplista de los problemas, pues dejo de lado dificultades tales como la debilidad institucional del Estado, problemas relacionados a la administración pública como el clientelismo y la corrupción (González, et al., 2009), sumado a ellos, se encontraron los inconvenientes propios de la representación política.

Por lo tanto, las nuevas reglas establecidas desde la Constituyente de 1991, las cuales contrarrestaban el bipartidismo, régimen caracterizado como la raíz de todos los problemas de la política en Colombia tanto por líderes de los partidos tradicionales como por jefes guerrilleros reinsertados, lograron adaptarse a las nuevas reglas, lo cual produjo inconvenientes tales como la individualización de la política, y con ello, a la perdida de las expresiones políticas y sus maquinarias en las regiones, convirtiendo a los partidos en microempresas electorales que no lograban articular las relaciones tradicionales entre los partidos tradicionales y las regiones, y de éstas con el nivel central.

Un ejemplo de lo anterior, fue el cogobierno de algunos grupos armados ilegales con los poderes locales, con lo que se demostraba el desarraigo de las maquinarias electorales locales con los partidos (González et al., 2009; Duque (s.f.).

Estos problemas se profundizaron con la penetración del narcotráfico en la política nacional y local, lo que llevó a una mayor deslegitimación de la clase política, tal fue lo ocurrido con el caso del gobierno de Ernesto Samper y la denuncia del financiamiento de su campaña con dineros provenientes de este negocio ilegal.

En esa coyuntura fue clave el papel del Congreso de la República en especial la Comisión de investigación y Acusación, pero tal entidad no sancionó el hecho y eso fue considerado lesivo para la política del país, generando una pérdida de su credibilidad. Las consecuencias del narcotráfico en la política, además de la deslegitimidad del régimen político, ha sido la de impactar en las instituciones del país, fragmentar y privatizar el poder (González, et al., 2009).

De esta suerte en los territorios ya no solo los partidos tradicionales se disputaban sus recursos económicos, a ellos llegaron actores como grupos armados ilegales y narcotraficantes que lucharon por el control de esos recursos, el control de los corredores geográficos y a cogobernar con autoridades locales (González, et al., 2009).

Sin embargo y a pesar de todos las críticas que se puedan exponer también es innegable que la Constitución de 1991 ha significado un cambio de legitimización del Estado a través de la transformación de las relaciones de éste con la sociedad a partir del reconocimiento de su pluralidad, la descentralización administrativa (elección popular de alcaldes y gobernadores) y fiscal, el fortalecimiento del control constitucional, el equilibrio de poderes, la ampliación de la democracia participativa por medio de la creación de mecanismos de participación ciudadana (González, et al., 2009).

No obstante, por los problemas que se evidenciaron posteriores a la Constitución de 1991 tales como: i. el personalismo político, ii. el gran número de agrupaciones políticas $y$, 
iii. la injerencia de grupos armados ilegales en los partidos políticos; todos éstos, definidos como inconvenientes que conllevaron a una crisis de representación política, fue necesario el planteamiento de reformas políticas que diseñaron cambios a la Carta Magna.

\subsubsection{Las reformas políticas}

Tras las reformas políticas acaecidas con la Constitución de 1991, fueron necesarias otras reformas constitucionales y legales en materia política y electoral para conseguir un sistema político más representativo y participativo.

Después de la Constitución de 1991 ocurrió un aumento desmedido de las listas y ese fenómeno se conoció como "operación avispa", es decir, la proliferación excesiva de nuevos partidos y a la disminución de los partidos tradicionales. Tal fenómeno trajo consigo dificultades tales como la ausencia de disciplina interna de las organizaciones políticas, el clientelismo, la corrupción, entre otros.

Es por eso que se desarrolló el Acto Legislativo 01 de 2003 con el cual se modificó el sistema electoral en Colombia básicamente en la reagrupación de los partidos políticos para dejar un número de organizaciones políticas más limitados y sólidos. Para ello definió un umbral mínimo de votación del 2\% para acceder a la curul del Senado y Corporaciones Públicas a nivel territorial; modificó la fórmula del cociente simple (método Hare) por la d'Hondt la cual favorece partidos robustos; incluyó las listas semi - abiertas con voto preferente opcional tanto para partidos como para ciudadanos; la cifra repartidora (artículo 263 constitucional, articulo 12 del Acto legislativo 01 de 2003); y la lista única con la cual se redujo la fragmentación interna de los partidos (Basset y Guevara, 2015; Hernández, 2009; Puyana, 2012).

Otra medida adoptada por la reforma política de 2003 fue la ley de bancadas, mecanismo diseñado para resolver la dificultad de que las múltiples agrupaciones políticas lograran llegar a consensos en el seno del Congreso. En este sentido el artículo 108 constitucional dispuso que los miembros de las corporaciones públicas elegidos por un mismo partido, movimiento político o ciudadano debían actuar como bancada (Hernández, et al., 2009)
Con esta reforma y la adopción del voto preferente opcional se llegó a la reagrupación de los partidos políticos atomizados en muchas agrupaciones a la conformación de un solo partido, y condujo a que los partidos políticos presentaran listas abiertas para que el elector eligiera el candidato de su preferencia. Pero esto significó en la practica un incremento de los personalismos y que las agrupaciones políticas continuaran sin democracia interna (Basset y Guevara, et al., 2015).

Para el 2005 se presentaron dos actos legislativos que reformaron el artículo 176 constitucional relativos a la conformación de la Cámara de Representantes, esta reforma política estaba constituida por el Acto legislativo 02 de 2005, con el cual crea la circunscripción internacional para elegir un representante de los colombianos residentes en el exterior.

De igual forma se constituyó por el Acto Legislativo 03 de 2005, el cual dispuso: dejar la representación mínima de dos curules por cada circunscripción electoral y que habría “(...) una representación adicional por cada 365.000 habitantes o fracción mayor de 182.500 sobre los primeros 365.000" (Vanegas, 2008, p. 79); que a partir del 2014 la base de asignación de curules se ajustaría de manera proporcional al crecimiento demográfico; conservar los departamentos y el distrito capital como circunscripciones electorales; mantener las circunscripciones electorales especiales para grupos étnicos y minorías políticas, con las que pueden elegir hasta 4 representantes; y que tales criterios se aplicarían a partir de las elecciones del 2010 en las circunscripciones territoriales para Cámara.

Tras la ocurrencia de varios escándalos por motivo de los congresistas involucrados en investigaciones por supuestas articulaciones con grupos armados al margen de la ley paramilitares- se dieron 40 condenas entre noviembre de 2007 y julio de 2013 por el asunto.

Al respecto, la investigación de la Corporación Nuevo Arco Iris determino que en un proceso de expansión de los paramilitares modificaron de manera sustancial el mapa político de 12 departamentos, conformaron una bancada parlamentaria, capturaron el poder local e influenciaron en el desmembramiento de los partidos políticos tradicionales: liberal y conservador, llevando al surgimiento de otros partidos que ejercieron un importante papel en el régimen político (Valencia, 2007). 
Además de lo anterior, por los escándalos en las relaciones entre los políticos y el narcotráfico se consiguió el desarrollo del Acto Legislativo 01 de 2009 (Reforma Política de 2009), la cual reforma el artículo 107 constitucional con el fin de atribuir responsabilidad a partidos y movimientos políticos que avalen candidatos electos o no, y que hayan sido condenados por delitos relacionados con: vinculación a grupos armados ilegales, actividades del narcotráfico, delitos contra los mecanismos de participación, delitos de lesa humanidad.

Las sanciones para estos delitos llevan multas, devolución de recursos públicos, prohibiciones por cierto tiempo para presentar candidatos y hasta la cancelación de la personería jurídica para la agrupación política (Perdomo, 2011).

La reforma política del 2009 estableció además de lo mencionado, la silla vacía consistente en la perdida de la curul para los miembros de la Corporación de elección popular y para el partido político cuando se hubiere hecho parte a la persona en procesos penales por causas como narcotráfico, delitos de lesa humanidad, vínculos con grupos armados ilegales. (Perdomo, et al., 2011; Puyana, et al., 2012).

También dispuso que la inscripción de candidato incurso en causal de inhabilidad sería revocada por el Consejo Nacional Electoral -CNE- (artículo 108 constitucional inciso 5o), asimismo mediante artículo 265 de la Constitución se le otorga al CNE la atribución de decidir sobre la revocatoria de la inscripción de candidatos a Corporaciones Públicas o cargos de elección popular en tanto exista prueba de que están incursos en una casual de inhabilidad (Vanegas, et al., 2009).

Posteriormente se aprobó la ley estatutaria 1475 de 2011 mediante la cual se estableció la obligación a los partidos políticos de que las listas presentadas a cuerpos colegiados en donde se elijan cinco o más curules se cuente en ellas para su conformación con al menos el $30 \%$ por uno de los dos géneros.

Esta ley introdujo modificaciones al régimen sancionatorio a los partidos, nuevos parámetros de financiación y una reglamentación a la consulta interna de los partidos como mecanismo de democratización interna de los mismos.
Medidas que en principio ayudarían a mejorar la representación política.

Sin embargo, se ha criticado que la permanencia de la lista abierta ha restado el impacto que esta reforma política debió proporcionar, dado que mantener tal figura implica permitir sus efectos adversos en la democracia interna de los partidos así como en la cuota de género (Basset y Guevara, et al., 2015).

Posteriormente el Acto Legislativo 01 de 2013 modifico el artículo 176 constitucional al ampliar la circunscripción electoral internacional a dos curules y eliminando la curul para minorías políticas, la cual se había asignado desde el 2002 con la ley 641 de 2001, medida que permitió la existencia de partidos minoritarios que no alcanzaban a elegir congresistas ni el umbral impuesto por la reforma política del 2003.

Tal fue el caso de la Alianza Democrática M-19 en el 2002, agrupación que obtuvo su personería jurídica en 2005 denominándose Partido Opción Centro, pronto se refundo como Partido Verde Opción Centro, y en las elecciones de 2010 como Partido Verde le eligieron 5 senadores y 3 representantes a las Cámara. En 2014 como Alianza Verde logró hacer elegir 5 senadores y 6 representantes, lo cual significa que debido a la curul de minorías políticas consiguió sobrevivir y consolidarse en partido político (KAS, et al., 2015)

También se cuenta con la reforma política del equilibrio de poderes, la cual en su proyecto de Acto Legislativo No. 018 de 2014 Senado /153 de 2014 Cámara, contemplaba la reforma de las circunscripciones en las que son elegidos los miembros del Congreso: Senado y Cámara.

Su pretensión era mejorar la representatividad de las principales Corporaciones Públicas y así contribuir a que el principio de equilibrio de poderes en su concepción amplia irradiará a un equilibrio en la participación de los distintos sectores de la población y grupos de interés así como de diferentes regiones en el Congreso (KAS, et al., 2015).

Dicho proyecto buscaba modificar el artículo 171 de la Constitución y resolver el problema de la representación en el Congreso equilibrando las curules con el peso demográfico de las 
regiones, por lo tanto proponía reducir las curules del Senado (de la circunscripción nacional) y crear circunscripciones uninominales en cada departamento con menos de 500.000 habitantes, esto es, eligiendo a un solo candidato y el que obtuviera el mayor número de votos (KAS, et al., 2015).

Después de su trámite en el Congreso fue aprobado el Acto Legislativo 02 de 2015 mediante el cual se adoptaron disposiciones relativas al sistema electoral; al régimen de nombramiento de servidores públicos; la prohibición de reelección del Presidente y Vicepresidente de la República; el régimen de investigación y juzgamiento del Presidente de la República y de los miembros de la Comisión de Aforados; el régimen de responsabilidad del Fiscal General de la Nación y de los magistrados de la Corte Constitucional, de la Corte Suprema de Justicia, del Consejo de Estado y de la Comisión Nacional de Disciplina Judicial; la forma de elección de los magistrados de la Corte Suprema y del Consejo de Estado; las funciones a cargo de la Corte Constitucional; el régimen de gobierno y administración de la Rama Judicial; las autoridades y régimen disciplinario de funcionarios y empleados de la Rama Judicial; la Contraloría y la Defensoría (Corte Constitucional, 2016).

Por medio de las sentencias C-285 y la C-373 de 2016, la Corte Constitucional declaro inexequible varias disposiciones del Acto legislativo de la referencia, como las modificaciones al sistema de gobierno y la administración judicial al declarar inexequible la creación del Consejo de gobierno y la Comisión de aforados, pero dejo vigente la prohibición de reelección del presidente de la República.

\section{CONCEPTO DE CIRCUNSCRIPCIÓN ELECTORAL}

\subsection{Definición y caracterización}

La circunscripción electoral es uno de los elementos que conforman un sistema electoral y es la demarcación o división territorial de los electores para que desde ese espacio puedan ejercer el derecho al sufragio, y para que esos votos a su vez se conviertan en escaños sin que interesen o interfieran los votos emitidos en otras circunscripciones (Vanegas, et al., 2008).

De esta forma según Juan Hernández Bravo (1999) la circunscripción electoral es el "ámbito personal y territorial del ejercicio del derecho al sufragio" (Vanegas, et al., 2008, p. 55) y se usa por lo general para elecciones parlamentarias.

Para su definición es necesario explicar los tres elementos que la componen, a saber, la magnitud, el tamaño y la amplitud.

El elemento de la magnitud se refiere al número de escaños que se eligen en cada circunscripción, ahora bien, el número de representantes a ocupar esos escaños puede ser establecido de muchas maneras, puede ir desde el fijar un número igual para todas las circunscripciones hasta señalar el número de puestos a partir por ejemplo de la población que reside en la circunscripción (Vanegas, et al., 2008).

El tamaño se refiere a su extensión física o territorial, según Francisco Fernández Segado (1993) esto lleva a analizar la geografía electoral. Y frente a la amplitud se hace alusión al número de la población que conforma la circunscripción que puede ser la población que habita el territorio o el número de ciudadanos que votan (Vanegas, et al., 2008)

La combinación de los elementos: número de población y número de curules a proveer, puede generar problemas relacionados con la igualdad en la representación electoral alprovocar situaciones de subrepresentación o sobrepresentación (Vanegas, et al., 2008)

Estos problemas se resuelven aplicando el principio de igualdad en las circunscripciones y estaría determinado por el número de habitantes de cada circunscripción y el número de curules a proveer a los representantes, es lo que Vanegas citando a Fernández Segado denomina "índice de representación poblacional" (Vanegas, et al., 2008).

Sin embargo lograr tal exactitud aritmética es complicado e implica añadir otros elementos que lleven a un buen resultado en términos de igualdad en representación, variables como la revisión del elemento de magnitud, las variaciones demográficas y las migraciones poblacionales. 
Por otro lado, es preciso mencionar a los tipos de circunscripción, los cuales se construyen a partir de la magnitud de las mismas y son por lo general uninominales y plurinominales. Las primeras son aquellas en las que se elige a un representante y se aplica en sistemas de representación proporcional, las segundas corresponden a aquellas en las que se eligen varios escaños y surgen de sistemas de mayoría (Nohlen, 1994).

En las circunscripciones plurinominales existen subtipos tales como circunscripciones pequeñas (se eligen de 2 a 5 escaños), medianas (se eligen de 6 a 10 escaños), circunscripción grande (eligen 10 y más escaños). Para Vanegas entre menor es la circunscripción, menor es la proporcionalidad y son reducidas las posibilidades de las fuerzas minoritarias de obtener escaños, en cambio, entre mayor sea la circunscripción la proporcionalidad tiene mayor efecto y los partidos minoritarios tienen mayor representación (Vanegas, et al., 2008).

En Colombia, el artículo 171 constitucional define que el Senado debe estar compuesto por 100 miembros electos en circunscripción nacional, esto significa que se puede votar por un candidato en cualquier parte del país y en el extranjero, a estos cien se suma dos miembros elegidos en circunscripción especial para los pueblos indígenas.

En el caso de la Cámara de Representantes, conforme al artículo 176 constitucional, está integrada por: miembros elegidos en circunscripciones departamentales más distrito capital, también se incluye circunscripciones especiales; dos curules para representantes de comunidades afro descendientes; dos curules para representantes de los colombianos en el exterior; y una curul a un representante de pueblos indígenas.

Se entiende por el diseño constitucional que el Senado se integra de representantes que obedecen a intereses de la nación, mientras que en la Cámara se representan los intereses de las regiones o grupos de interés (Vargas, et al., 2015).

Como se dijo previamente, un problema real para la representatividad es el peso demográfico el cual tiene relación con la cantidad de congresistas que se elige en cada región (Vargas,
2015). Desde el análisis a las elecciones del 2014, se sabe que 5 de los 100 senadores electos en circunscripción nacional consiguen más del $50 \%$ de sus votos en un solo departamento, y de ellos, 10 concentran más del $80 \%$ de su votación en un solo departamento, lo que obliga a concluir que para el Senado aunque la circunscripción es nacional esto no implica que los senadores tengan una representatividad fuerte en una región determinada.

Lo anterior se evidencia en que por ejemplo las región caribe (Guajira, Magdalena, Cesar, Atlántico, Bolívar, Sucre y Córdoba) y la región suroriental (Vichada, Guania, Guaviare, Vaupés y Amazonas) tienen una alta participación, pero mientras la primera es la que más senadores elige, la segunda no elige a ninguno (Vargas, et al., 2015).

En este orden, tenemos en primer lugar, que las zonas afectadas por la violencia son precisamente los departamentos con menos posibilidad de elegir congresistas lo que significa un desequilibrio al acceso de la representación en esta Corporación pública y de la participación de estos sectores poblacionales $\mathrm{y}$ regionales en la misma.

En segundo lugar, que en principio se podría pensar que las circunscripciones especiales de paz buscan aumentar la representación en la Cámara de Representantes, precisamente porque es ésta la corporación que debe canalizar la representación de cada departamento, contrario al Senado que canaliza la representatividad a nivel nacional.

Finalmente, por la estrecha relación entre circunscripción electoral y representación política es necesario definir sobre este concepto.

\subsection{Una breve definición sobre la representación política: el caso Colombiano}

La representación está articulada a la democracia y al concepto de lo público, y aceptar tal asociación implica que el representante actúa en nombre de un representado para la satisfacción de los intereses de ese representado pero siempre acorde con la ley (Medellín, 2005)

Para Sartori (1992) existen tres niveles de representación: la jurídica, la sociológica y la política, al respecto señala que: 
"La representación política está emparentada con la idea de control y de responsabilidad del representante. El representante lo es porque se somete a la fiscalización de sus representados. El elegido debe actuar con responsabilidad respecto de las exigencias de la ciudadanía que lo sostiene, debiendo lograr que se cumplan las exigencias normativas de esa sociedad, de manera que si no son satisfechas le será retirada la confianza" (Medellín, et al., 2005, p. 20).

Pero la representación política no está ligada solamente a la relación representado representante, significa también la acción de las instituciones. De esta forma la representación tiene dos ámbitos, el primero, el ámbito de las formas de representación a través de cuerpos sociales que pueden constituir una fuerza política alrededor de intereses; el segundo, es el ámbito de las instituciones que otorgan representatividad a quienes toman decisiones en ellas (Medellín, et al., 2005).

Frente a las formas de representación, los partidos políticos, el gobierno y el parlamento constituyen el principal espacio de representación. En el equilibrio de poderes el parlamento constituye la fuerza contra hegemónica del ejecutivo por lo que su heterogeneidad y representación de los diversos intereses 'provenientes de los grupos sociales y sectoriales, es de gran importancia.

Como se evidencio previamente, en Colombia el frente nacional con la hegemonía de dos partidos tradicionales: liberal $y$ conservador, y luego con el personalismo de la política, llevaron a una crisis de las formas de representación política, y también a una crisis de representatividad al darse escándalos que involucraron al ejecutivo y especialmente al Congreso: "el proceso 8000" y la "parapolítica". Tales dificultades llevaron a que después de la Constitución de 1991 se desarrollaran propuestas de reformas políticas para rectificarlas, es decir, Colombia presencia desde tiempo atrás una crisis de representatividad en tanto las instituciones se deslegitimaron en sus atributos de valor y estabilidad. Crisis incrementada con las fuentes de financiaron ilegal de los partidos y su accionar en los poderes públicos, además de un ejercicio legislativo que queda solamente en aprobar o no proyectos de una agenda del ejecutivo a cambio de retribuciones en dinero o en cargos burocráticos (Medellín, 2005).

\section{EL ACUERDO DE PAZ Y LA PROPUESTA DE LAS CIRCUNSCRIPCIONES ESPECIALES DE PAZ}

\subsection{El Acuerdo Final de Paz}

El 16 de octubre de 2012, el presidente Juan Manuel Santos inicio un proceso de diálogos con la guerrilla de las Fuerzas Armadas Revolucionarias de Colombia- Ejército del Pueblo (FARC-EP) en Oslo - Noruega, dicho proceso fue desarrollado en la Habana- Cuba y en él se definió seis puntos centrales de la agenda de negociación: i. Política de desarrollo agrario, ii. Participación política, iii. Fin del conflicto, iv. Solución al problema de las drogas ilícitas, v. Víctimas e implementación, vi. Verificación y refrendación de los acuerdos.

El proceso en la Habana concluyó el 24 de agosto de 2016 y llevo a la firma del Acuerdo de paz denominado "Acuerdo Final para la Terminación del Conflicto y la Construcción de una Paz Estable y Duradera" el 24 de noviembre de $2016^{1}$.

Este Acuerdo Final de Paz busca limitar situaciones que han estado relacionadas con el conflicto armado interno y para ello dispone de un conjunto de propuestas, las cuales se han definido a partir del reconocimiento de una serie de fenómenos que si bien no son entendidos como las causas objetivas de la violencia, si son explicativos de la prolongación del conflicto, estos elementos son por ejemplo: una deficiente gestión del desarrollo rural, limitaciones democráticas y el narcotráfico (Londoño, 2017).

Dentro de esas propuestas se encuentran reformas políticas que atienden esas limitaciones democráticas, en este punto es importante resaltar que si bien después de la Constitución de 1991 se han presentado varias reformas políticas, ahora nos hallamos por primera vez

1. El Acuerdo Final fue inicialmente firmado en Cartagena el 26 de septiembre de 2016 y fue sometido el 2 de octubre de ese año a votación del pueblo mediante la figura del plebiscito ganando el no por un porcentaje del $0.47 \%$. De esta suerte la mesa de diálogos de la Habana recogió e incorporó las propuestas de los líderes de campaña de quienes propugnaron por el No, eso llevo a un nuevo Acuerdo firmado el 24 de noviembre de 2016. 
desde la Constitución de 1991 ad portas a la implementación de una serie de reformas políticas producto de un proceso de paz.

Estas reformas políticas buscadas a la par con la paz permite por primera vez que todos los actores acepten las reglas de juego electoral, ya que básicamente antes del proceso de paz, los certámenes electorales y la democracia política coexistían con altos grados de violencia del conflicto.

Dicho de otra forma, en Colombia se presentó que grupos armados ilegales usaron la violencia como herramienta para acceder al poder y por ello, el país se mantuvo en una democracia incompleta (Londoño, et al., 2017).

Es así que el punto dos del Acuerdo Final: "Participación Política y apertura democrática" busca mejorar la democracia del país en un contexto donde no se combinen las armas y la política, lo que implica una apertura de la institucionalidad a nuevas fuerzas que por el conflicto no han podido ejercer de manera plena los derechos políticos y civiles. (Londoño, et al, 2017).

Es por eso que con el Acuerdo Final no se busca solamente la participación política de las FARC, como ocurrió en procesos anteriores con otros grupos armados al margen de la ley, sino que además de esto, se pretende cambiar las reglas del sistema democrático colombiano.

En consecuencia, el Acuerdo de paz en el punto dos marca como ejes fundamentales los siguientes: el ejercicio de la oposición; la reforma electoral; los mecanismos de participación ciudadana y el sistema de partidos; y las medidas para promover la mayor participación en la política nacional y local.

Así mismo, establece como pilares en este punto, los siguientes, primero, la nueva apertura democrática que implica la búsqueda de la inclusión política como forma para consolidar la paz. Para ello aborda la creación de partidos políticos y de circunscripciones especiales de paz, así como el incremento de la participación política.

El segundo pilar se dirige a una participación ciudadana e incluye garantías de participación para organizaciones y movimientos sociales. El tercer pilar corresponde a romper el vínculo entre política y armas. (Londoño, et al., 2017)

En este orden, es fundamental enfatizar que la "Apertura democrática" significa "(...) una apertura de la institucionalidad y del sistema en donde se permita el surgimiento de nuevas fuerzas que en virtud del conflicto armado no han podido ejercer sus derechos civiles y políticos" (Londoño, et al., 2017, pp. 6, 8,9).

El precepto de "apertura democrática" se enmarca, por un lado, en tanto el Acuerdo Final de Paz se ubica dentro del concepto de justicia transicional, definida como un conjunto de procesos y mecanismos para resolver los problemas de un pasado de abusos y violaciones a los derechos humanos, por lo que involucra soluciones y herramientas a las sociedades para cumplir con objetivos tales como la reconciliación nacional y la consolidación de la democracia.

Por otro lado, desde una concepción de paz que no significa solamente la ausencia de conflicto, y precisamente más allá de la temporalidad del postconflicto y de la justicia transicional, Boutros Boutros Ghali que para 1991 era Secretario de las Naciones Unidas, definió que la construcción de paz significa “(...) medidas destinadas a individualizar y fortalecer estructuras que tiendan a reforzar y consolidar la paz a fin de evitar una reanudación del conflicto" (Walteros, 2011, p. 17).

Por lo tanto, en Colombia que se ha presentado una "democracia incompleta" dado que no puede existir democracia donde no se respeten los derechos humanos (Carpizo, 2009), consolidarla implica tomar medidas desde el postconflicto pero que trasciendan su temporalidad y se queden en las prácticas políticas de la sociedad colombiana y en las instituciones públicas.

Lo cual permitiría enfrentar problemas tales como el de la representación política, sobre todo, de aquellos que fueron excluidos de la participación política y pertenecientes de aquellas regiones que han sido golpeadas por el conflicto.

Estas garantías de consolidación de la democracia son fundamentales para fortalecer la credibilidad en las instituciones públicas, en el caso de las Circunscripciones especiales de paz, para permitir una representación de personas 
que han vivido en las regiones afectadas por el conflicto y conocen sus realidades territoriales, de ahí que la implementación de esta figura debe darse de forma adecuada (Ochoa, 2010).

\subsection{Las Circunscripciones Transitorias Especiales de Paz.}

\subsubsection{Las Circunscripciones en el Acuerdo Final de Paz}

El Acuerdo Final para la Terminación del Conflicto y la Construcción de una Paz Estable y Duradera en el punto 2.3.6., dispone la Promoción de la representación política de poblaciones y zonas especialmente afectadas por el conflicto y el abandono, estableciendo que:

- Con el objetivo de que las zonas más afectadas por el conflicto, el abandono y débil presencia institucional, logren una mayor inclusión y representación política de sus poblaciones y garantía de sus derechos políticos, es necesario adoptar una medida de reparación y construcción de paz, consistente en la creación de 16 Circunscripciones Transitorias Especiales de Paz para elegir 16 representantes a la Cámara por dos periodos electorales.

- Tales Circunscripciones contaran con reglas especiales para la inscripción $y$ elección de candidatos, las campañas tendrán financiación especial así como acceso a medios regionales, de igual forma se definirán mecanismos especiales de acompañamiento para la transparencia electoral y la libertad del voto.

- Los candidatos serán personas que habitan regularmente estos territorios que cubre las Circunscripciones o que hayan sido desplazados y estén en proceso de retorno, podrán ser inscritos por grupos significativos de ciudadanos u organizaciones ubicadas en la Circunscripción como organizaciones campesinas, de víctimas, mujeres $\mathrm{y}$ sectores sociales que trabajen por la paz, para ello el gobierno nacional desarrollara procesos de fortalecimiento de estas organizaciones sociales, sobre todo las organizaciones de víctimas.
- Los candidatos serán elegidos por los ciudadanos de estos territorios sin perjuicio de que estos ciudadanos puedan votar en la elección de candidatos de Cámara de Representantes en las elecciones ordinarias.

- Los partidos políticos que tengan representación en el Congreso o con personería jurídica incluido el partido político que surja de las Farc no podrán inscribir candidatos para estas Circunscripciones.

- La organización electoral ejercerá una especial vigilancia sobre el cenco electoral, inscripción de candidatos y financiación de campañas, adicional a ello, se promoverá medidas de control y veedurías por organizaciones especializadas como la Misión de Observación Electoral (MOE), partidos y movimientos políticos.

\subsubsection{Contenido del proyecto de Acto Legislativo que regula las Circunscripciones Transitorias de paz}

En desarrollo del Acuerdo de Paz (punto 2.3.6) $\mathrm{y}$ mediante el procedimiento legislativo especial o "fast track" se está llevando en el Congreso de la República el trámite del Acto Legislativo"Por medio del cual se crean 16 Circunscripciones Transitorias Especiales de Paz para la Cámara de Representantes en los periodos 2018 - 2022 y 2022 - 2026", dicho trámite surtió el primer debate el 6 de junio del año en curso en Comisión Primera de Senado y fue modificado en segundo debate en la Plenaria de Senado. El proyecto en lo que lleva de trámite, sostiene que:

-En cuanto a la conformación de las Circunscripciones de paz

La Cámara de Representantes tendrá 16 representantes más para los períodos constitucionales 2018 - 2022 y 2022 - 2026, los cuales serán elegidos uno por cada una de dichas Circunscripciones ${ }^{2}$.

2. Las Circunscripciones Transitorias Especiales de Paz se conformarían de la siguiente forma:

“Circunscripción 1

Municipios del Cauca: Argelia, Balboa, Buenos Aires, Caldono, 
Caloto, Cajibío, Corinto, El Tambo, Jambaló, Mercaderes, Morales, Miranda, Patía, Piendamó, Santander de Quilichao, Suárez y Toribío. Municipios de Nariño: Cumbitara, El Rosario, Leiva, Los Andes, Policarpa y los municipios de Florida y Pradera, Valle del Cauca.

Circunscripción 2

Conformada por Arauquita, Fortul, Saravena y Tame. Departamento de Arauca.

Circunscripción 3

Municipios del departamento de Antioquia: Amalfi, Anorí, Briceño, Cáceres, Caucasia, El Bagre, Ituango, Nechí, Remedios, Segovia, Tarazá, Valdivia, Zaragoza.

Circunscripción 4

Constituida por 8 municipios de Norte de Santander: Convención, El Carmen, El Tarra, Hacarí, San Calixto, Sardinata, Teorama y Tibú.

Circunscripción 5

Municipios del departamento del Caquetá: Florencia, Albania Belén de Los Andaquíes, Cartagena del Chairá, Curillo, El Doncello, El Paujil, Montañita, Milán, Morelia, Puerto Rico, San José de Fragua, San Vicente del Caguán, Solano, Solita y Valparaiso, y el Municipio de Algeciras del Departamento del Huila.

Circunscripción 6

Municipios del Departamento de Choco: Bojayá, Medio Atrato Itsmina, Medio San Juan, Litoral de San Juan, Novita, Sipi, Acandí, Carmen del Darién, Riosucio, Unguía, Condoto y dos municipios de Antioquia Vigia del Fuerte y Murindo.

Circunscripción 7

Municipios del departamento del Meta: Mapiripán, Mesetas, La Macarena, Uribe, Puerto Concordia, Puerto Lleras, Puerto Rico y Vistahermosa y 4 municipios del departamento del Guaviare San José del Guaviare, Calamar, El Retorno y Miraflores.

Circunscripción 8

Municipios del departamento de Bolívar: Córdoba, El Carmen de Bolívar, El Guamo, María La Baja, San Jacinto, San Juan de Nepomuceno y Zambrano. Municipios de Sucre: Colosó, Chalan, Los Palmitos, Morroa, Ovejas, Palmito, San Onofre y Toluviejo. Circunscripción 9

Municipios del Cauca: Guapi, López de Micay y Timbiquí Buenaventura, del departamento del Valle del Cauca.

Circunscripción 10

Está constituida por 11 municipios del departamento de Nariño: Barbacoas, El Charco, La Tola, Maguí, Mosquera, Olaya Herrera, Francisco Pizarro, Ricaurte, Roberto Payan, Santa Barbara y Tumaco.

Circunscripción 11

Municipios del departamento del Putumayo: Orito, Puerto Asís, Puerto Caicedo, Puerto Guzmán, Puerto Leguízamo, San Miguel, Valle del Guamuez y Villagarzón

Circunscripción 12

Municipios del Cesar: Agustín Codazzi, Becerril, La Jagua de Ibirico, La Paz, Pueblo Bello y Valledupar. Municipios de La Guajira: Dibulla, Fonseca, San Juan del Cesar. Municipios del Magdalena: Aracataca, Santa Marta, Ciénaga y Fundación.

Circunscripción 13

Municipios del departamento de Bolívar: Arenal, Cantagallo, Morales, San Pablo, Santa Rosa Del Sur y Simití y el municipio de Yondo del departamento de Antioquia.

Circunscripción 14

Municipios de Córdoba: Puerto Libertador, San José de Uré, Valencia, Tierralta y Montelibano.

Circunscripción 15
- Sobre la forma y reglas de elección

- Cada Circunscripción transitoria de paz elegirá un Representante a la Cámara, de la siguiente manera: primero, las listas tendrán voto preferente; segundo, se integrarán por dos candidatos, al menos uno de ellos deberá acreditar su condición de víctima del conflicto armado interno; tercero, la curul se asignara a la lista con mayor cantidad de votos ${ }^{3}$.

- Las Circunscripciones contarán con reglas especiales para la inscripción y elección de candidatos.

- Los candidatos deben acreditar los requisitos generales señalados en la Constitución y la ley para ser Representantes a la Cámara, además de ello, primero, haber habitado en el territorio de la respectiva circunscripción los 3 años previos de la votación; segundo, en el caso de los desplazados, deben encontrarse en proceso de retorno con la intención de establecerse en el territorio, haber nacido o habitado en ese lugar al menos 3 años seguidos en cualquier época.

- En el caso de las víctimas del conflicto armado, se debe aportar la certificación de la Unidad para las víctimas o del Ministerio Público mediante acto administrativo.

- Los candidatos sólo pueden ser inscritos por organizaciones de víctimas, grupos significativos de ciudadanos (GSC), campesinos, organizaciones sociales, incluyendo las de mujeres.

- Por organización social se entiende las asociaciones de todo tipo sin ánimo de lucro pero que demuestren su existencia con personería jurídica reconocida 4 años antes de las elecciones, o mediante acreditación de la autoridad electoral competente.

Municipios del departamento del Tolima: Ataco, Chaparral, Planadas y Rioblanco.

\section{Circunscripción 16}

Municipios del departamento de Antioquia: Carepa, Chigorodó Dabeiba, Mutatá, Necoclí, San Pedro de Urabá, Apartadó y Turbo .

3. Estas disposiciones se incluyeron en el debate de Plenaria de Senado, lo cual significa que de los 16 representantes a la Cámara al menos 8 serán víctimas del conflicto armado interno. 
- La inscripción de candidatos por GSC necesitará el respaldo ciudadano correspondiente al 3\% del censo electoral de la circunscripción de paz, en ningún caso se requerirá más de 3000 firmas.

- Cuando la circunscripción coincida en todo o en parte con los territorios étnicos, podrán inscribir candidatos: los consejos comunitarios; los resguardos y las autoridades indígenas en sus territorios, debidamente reconocidos, en coordinación con sus respectivas organizaciones nacionales; las Kumpañy legalmente constituidas.

- Los municipios incluidos en estas Circunscripciones que superen los 50.000 ciudadanos aptos para votar, se habilitara en ellos los puestos de votación y el censo electoral rural y se excluirá el censo electoral y puesto de votación de la cabecera municipal.

- La votación de las circunscripciones transitorias especiales de paz no tendrá en cuenta el umbral de acceso a la repartición de curules en la elección ordinaria de Cámara de Representantes.

- Las elecciones de los representantes a la Cámara de las circunscripciones de paz se harán en el mismo día de las elecciones del Congreso de la República para los años 2018 y 2022.

- Los ciudadanos podrán ejercer su derecho al voto en estas circunscripciones especiales de paz, sin que ello signifique que no pueda votar por candidatos a la Cámara de Representantes en las elecciones ordinarias.

- La votación de las circunscripciones transitorias de paz se hará en tarjeta separada de las circunscripciones ordinarias para Cámara de Representantes.

\section{- Sobre la financiación de campañas}

- Las campañas contarán con financiación especial y acceso a medios regionales.

- Será preponderamente estatal, mediante sistema de reposición de votos y acceso de anticipos. Los anticipos equivaldrán al 50\% del resultado de multiplicar el valor del voto a reponer por el número de ciudadanos que conforman el cenco electoral de la determinada circunscripción.
- Los particulares podrán contribuir al financiamiento de estas campañas mediante donaciones hechas al Fondo Nacional de Partidos y Campañas Electorales. Tales donaciones no podrán ser superiores al $10 \%$ del monto establecido para Cámara de Representantes.

- No se admiten aportes privados.

- La publicidad en medios de comunicación se harán solo en espacios gratuitos otorgados por el Estado.

- Respecto a garantías especiales y electorales

- Para poblaciones apartadas y centros poblados dispersos de las zonas rurales se garantizará nuevos puestos de votación ${ }^{4}$.

- Los candidatos impulsados por organizaciones de víctimas, contarán con un régimen especial que les permitirá tener facilidades para su inscripción en estas circunscripciones, entre esas medidas, se encuentra la financiación estatal anticipada no reembolsable. Tal régimen especial deberá ser reglamentado por el gobierno nacional.

- La organización electoral adoptara medidas de actualización y vigilancia del censo electoral, así mismo se garantizara la participación real y efectiva de los pueblos étnicos a través de la inscripciones de sus cedulas, la pedagogía del voto y la instalación de puestos de votación en sus territorios.

- La autoridad electoral pondrá en marcha Tribunales electorales transitorios de paz tres meses antes de las elecciones ${ }^{5}$

-

- Sobre prohibiciones, sanciones y suspensiones.

- El gobierno nacional reglamentará el sistema de sanciones para aquellos que sean elegidos en las circunscripciones transitorias de paz y no cumplan con las reglas establecidas en el acto legislativo.

4. Nuevo artículo que se incluye en Plenaria de Senado.

5. Disposición que se integra en debate de Plenaria del Senado pero que se dispuso en el Acuerdo de Paz entre las Farc y el gobierno nacional. 
- Los partidos y movimientos políticos con personería jurídica o que tienen representación en el Congreso de la República, incluido la agrupación política que surja de las FARC-EP, no podrán inscribir listas ni candidatos para estas Circunscripciones.

- Los miembros de los grupos armados ilegales que hayan suscrito acuerdos de paz o se hayan desmovilizado en los últimos 10 años, no podrán ser candidatos de estas circunscripciones

- Se prohíbe que grupos significativos de ciudadanos y organizaciones sociales inscriban listas de candidatos para las circunscripciones de paz de manera simultánea con otras circunscripciones.

- No podrán presentarse como candidatos quienes hayan sido elegidos o no, a cargos públicos con el respectivo aval de partidos o movimientos políticos con personería jurídica y durante el año anterior a la elección de las circunscripciones de paz no hayan renunciado al cargo o al rol en la dirección de la agrupación política ${ }^{6}$.

- Adicionalmente por razones de orden público el Presidente de la República podrá suspender la elección en cualquier de los puestos de votación de las 16 circunscripciones conforme al concepto del sistema de Alertas tempranas de la Defensoría del Pueblo, de la Procuraduría General dela Nación, la Registraduría Nacional del Estado Civil y la oficina del Alto Comisionado de las Naciones Unidas en Colombia ${ }^{7}$.

\subsubsection{Observaciones a la propuesta de las Circunscripciones de Acto} Legislativo incorporadas en el proyecto

- Dentro de las características generales se tiene que:

6. Disposición que se integra en el debate en Plenaria de Senado.

7. Este artículo se incluyó en el proyecto debatido en Plenaria de Senado, con él se busca impedir que en los sitios que comprenden las circunscripciones, muchos de los cuales en la actualidad se encuentran afectados por violencia y cultivos ilícitos, sean manipulados los certámenes de votación por grupos armados ilegales y grupos criminales. Tal régimen abre la posibilidad de que el Presidente de la República cancele elecciones en puestos de votaciones si se evidencia amenazas en alguna de las 16 circunscripciones.
- Las 16 Circunscripciones funcionaran en 167 municipios en 18 departamentos.

- Cada Circunscripción es uninominal pues entrega una curul a la Cámara en los periodos establecidos.

- De los 167 municipios, 14 de ellos excede los 50.000 ciudadanos, por lo que en ellos las Circunscripciones solo cubrirán la zona rural ${ }^{8}$.

- Los 167 municipios concentran el 7.6\% del censo electoral del país (2.688.159 ciudadanos) y su área territorial corresponde al 34\% de Colombia.

- El $71 \%$ de los consejos comunitarios del país así como el $45 \%$ de los cabildos indígenas se encuentran en los municipios que cubre las Circunscripciones.

- El 46\% (77 municipios) de los 167 municipios cubiertos por las Circunscripciones, podrían tener déficit de cedulación, el 70\% (116 municipios) podrían tener difícil acceso a puestos de votación.

- En las circunscripciones se congrega el $36 \%$ de todas las víctimas de violencia política, social y comunal desde 2016 hasta abril de 201.

- Una tercera parte de las circunscripciones tuvo riesgo en las elecciones de 2016 (el Plebiscito) por presencia del ELN, Bandas Criminales y minería ilegal, además el 76\% de los municipios tenia cultivos ilícitos en 2015.

- El acto legislativo deberá reglamentarse mediante ley estatutaria la cual debe promulgarse antes del inicio de la inscripción de candidatos a las elecciones del 2018 conforme Calendario Electoral, esto es, el 11 de noviembre de 2017 (MOE, 2017).

- El concepto de equilibrio de poderes implica también el equilibrio en la participación que tienen los distintos sectores de la sociedad y de las distintas regiones en las corporaciones públicas del nivel nacional (Vargas, 2015), y

8. Según la MOE (2017) los municipios son: Santander de Quilichao (Cauca), Caucasia (Antioquia), Florencia (Caquetá), El Carmen del Bolívar (Bolívar), Buenaventura (Valle), Tumaco (Nariño), Valledupar (Cesar), Santa Marta (Magdalena), Ciénaga (Magdalena), Fundación (Magdalena), Tierraalta (Córdoba), Montelíbano (Córdoba), Turbo (Antioquia), Apartado (Antioquia). 
esta iniciativa de las Circunscripciones especiales de paz corresponde a ello.

Es importante señalar que el proyecto sobre Circunscripciones de paz radicado en Congreso y decidido en primer debate, establecía que la razón de ser de las circunscripciones correspondía principalmente al enfoque territorial dado a que se concebían las circunscripciones para territorios afectados por la violencia.

Con el proyecto debatido y aprobado en segundo debate (Plenaria de Senado), se tuvo en cuenta para la conformación de las circunscripciones de paz no solo el criterio territorial, también el criterio poblacional y sectorial, de aquellos que fueron excluidos del ejercicio de la política tal como dispone el punto 2.3.6., del Acuerdo Final de paz.

En ese sentido se está hablando de sectores tales como las víctimas de graves violaciones a los derechos humanos, lo cual constituye una forma de reparación colectiva en tanto muchas de ellas fueron víctimas por el rol de liderazgo político, social o comunitario en sus territorios.

Es más en muchos de estos territorios los derechos políticos a la organización, oposición, protesta, movilización, fueron motivos para que muchas personas les fueran violados sus derechos humanos.

A la luz de los derechos humanos toda víctima de violaciones a los derechos humanos e infracciones al derecho internacional humanitario es titular de los derechos a la verdad, justicia y reparación integral, sin embargo en Colombia, la reparación a las víctimas del conflicto armado interno aun es tarea pendiente (Centro Internacional para la justicia transicional, 2010) sobre todo en materia de sus derechos políticos9.

9. Si bien se ha declarado superado el estado de cosas inconstitucional de las victimas desplazadas en materia de participación por la Corte Constitucional mediante Auto 373/16, es evidente que aún estos derechos políticos deben ser reparados. En dicho Auto la Corte señala que "En este orden de ideas, se procederá a declarar superado el Estado de Cosas Inconstitucional frente a este componente de la política pública, pues la población desplazada en el país cuenta con un esquema robusto de participación que estableció de manera clara y definida los espacios y las condiciones necesarias para la participación, y que a pesar de las dificultades que aún se presentan en materia de garantías e incidencia, las autoridades cuentan con los mecanismos para adoptar las correcciones que permitan garantizar progresiva y sostenidamente la plena satisfacción del derecho".
Por lo tanto una observación es que fue positivo que en el proyecto de Acto legislativo sobre Circunscripciones de Paz, se incluyera en segundo debate de forma taxativa a todas las víctimas del conflicto armado como sujetos que podrían participar dichas circunscripciones especiales conforme a lo establecido en el Acuerdo final de paz. Lo anterior tomando en consideración que el proyecto en primer debate contemplaba solamente a las víctimas desplazadas que se encontraban en proceso de retorno a los territorios ubicados en las 16 circunscripciones.

En el proyecto de Acto legislativo, salgo los grupos significativos de ciudadanos, no se exige umbral alguno $y$ eso se considera positivo en tanto la temporalidad (2018 - 2022 y 2022 - 2026) permite el fortalecimiento de la representación política en las circunscripciones especiales de paz y la capacidad de acción político electoral.

Una observación a tener en cuenta es que las circunscripciones requiere un manejo político distinto al monopolio centralista, lo que significaría que tales regiones y sus grupos políticos deben ser reconocidos realmente para no impedir su renovación política, local y regional. (Fals, 2000).

Esto significa que es importante la no obstaculización por parte de los poderes centrales de la participación plena y el goce de los derechos políticos de quienes participen en las circunscripciones de paz.

Lo anterior teniendo en cuenta el antecedente de la UP, pues el CNE en tiempo pasado declaro la perdida de la personería jurídica de esa agrupación política debido a que no había alcanzado el umbral exigido (3\%), sin tener en consideración de que se trata de una víctima colectiva del conflicto armado interno.

Por tal razón, el Consejo de Estado en el 2013 determinó que la UP no debió perder la personería jurídica y que ha debido mantenerla. De igual forma mediante consulta a la Sala de Consulta y Servicio Civil del Consejo de Estado la entidad definió que en el caso de la UP la personería debió mantenerse y reconoció la necesidad de que la agrupación gozara de un periodo de transición para recuperar su capacidad de acción político electoral (CNE, M.P. Novoa). 
El proyecto de Acto legislativo se refiere a un financiamiento especial, y es sabido que un asunto de gran importancia en los sistemas democráticos es el financiamiento de los partidos y de las campañas política, principalmente porque "El funcionamiento del principio democrático requiere igualdad no sólo en cuanto a la ecuación un ciudadano: un voto, sino también la necesaria para una competencia electoral con igualdad de oportunidades para todos los competidores"(Roll y Cruz, 2010, p. 22).

Así mismo porque el financiamiento de las campañas políticas se han incrementado en sus costos en los últimos años, lo que obliga a la imposición de mecanismos de regulación fuertes que impidan la incursión de recursos económicos ilegales en las definiciones de las autoridades políticas o la influencia de grupos económicos poderosos en las decisiones de política pública y de Estado (Roll y Cruz, et al., 2010).

En Colombia es evidente la captura del Estado por algunos grupos ilegales a través del financiamiento de la política en los ámbitos local y regional, y esto se demuestra con los dos casos mencionados previamente: el llamado "Proceso 8000" en la campaña presidencial de Ernesto Samper, y las AUC por su presunta infiltración en el Congreso con financiación directa y participación en campañas política durante el 2002 y 2006 (Roll y Ballén, et al., 2010).

El financiamiento de la política en Colombia está regulado “(...) por el articulo No 109 de la Constitución política de 1991 y por las leyes 10 de 1994; 616 de 200; 996 de 2005; así como por las Resoluciones 5304/2003; 4904/2003 y 1428/2004 del Consejo Nacional Electoral" (Roll y Ballén, 2010, p. 57).

Este marco normativo establece que el sistema de financiación de los partidos y campañas políticas es de un sistema mixto, es decir, que los fondos (en dinero o especie) provienen de fondos públicos y privados. Tal financiamiento público se realiza a través del Fondo Nacional de Financiación de Campañas creado por la ley 130 de 1994 (artículo 130) (Roll y Ballén, et al., 2010).

A pesar de tal regulación se tiene que frente al financiamiento de los partidos y las campañas políticas en Colombia, es reducido el control por parte del CNE, entidad administrativa que solo impone sanciones de tal orden como multas por la no presentación de informes o la no reposición de votos; además de ello, se cuenta con un Código Electoral desactualizado; y con la práctica de que los informes presentados por los partidos no contienen toda la información de los gastos incurridos en campañas ni de los financiadores (Roll y Ballén, et al., 2010).

Es notable que el financiamiento irregular afecta la competencia política, por tal motivo otra observación positiva al Proyecto de Acto legislativo, es que las agrupaciones y sus campañas políticas en las circunscripciones especiales de paz deban ser financiadas el ciento por ciento con recursos públicos ${ }^{10}$.

Esto en parte a que las zonas afectadas por la violencia son territorios con mayores niveles de pobreza, débil presencia del Estado, mayor presencia de grupos ilegales, y todas estas condiciones pueden facilitar el financiamiento irregular y por ende la captura de estas nuevas agrupaciones por los grupos políticos tradicionales o por grupos armados al margen de la ley.

\section{CONCLUSIONES}

El crear las condiciones, instrumentos y mecanismos necesarios para que las poblaciones históricamente excluidas de la participación política y pertenecientes a las regiones más golpeadas por el conflicto armado interno logren una mayor representación en la Cámara de Representantes, constituye la materialización del artículo $1^{\circ}$ constitucional que señala a Colombia como una república democrática, participativa y pluralista, en donde la participación de los ciudadanos en los asuntos públicos es un valor constitucional y esencial del Estado democrático y de derecho.

Por ende, el cumplimiento de tal precepto supone mejorar la representación, la participación y la gobernabilidad tal como se estipula con la iniciativa de las circunscripciones especiales de paz.

No obstante, es imperioso plantear algunas consideraciones finales sobre el proyecto del Acto legislativo, a saber:

10. Esta disposición fue añadida en segundo debate del proyecto. 
- Un punto de partida previo a la implementación de la norma debería ser el evaluar cómo la violencia del conflicto armado afectó los derechos políticos de los líderes y poblaciones que residen en las regiones que conforman las circunscripciones especiales, para que con dicha información se puedan ofrecer las garantías necesarias para una participación plena de la población residente en dichos territorios.

- Existe preocupación frente a la persecución, amenaza y homicidio de líderes regionales, que conforme al informe de riesgo del 30 de marzo de 2017 de la Defensoría del Pueblo, gran parte de los municipios identificados en riesgo corresponde a los que integran las Circunscripciones.

- Aunque el proyecto de Acto legislativo toma medidas previsivas, no deja de inquietar la posibilidad de que políticos tradicionales así como grupos armados ilegales coopten o limiten a las agrupaciones políticas que actuarían en estas Circunscripciones.
- También preocupa que en las regiones las organizaciones sociales que históricamente se han ayudado, entren en disputa por la curul o puesto de representación.

- $\quad$ Es probable que los grupos significativos de ciudadanos que se presenten para las circunscripciones electorales especiales de paz logren la personería jurídica y sigan representando a sus territorios más allá del tiempo establecido en el proyecto.

- Finalmente, se concluye que el proyecto de Acto legislativo sobre circunscripciones especiales transitorias de paz, contempla medidas tendientes a resolver el problema de la subrepresentacion de sectores y regiones afectados por el conflicto armado interno, ya que favorece el enfoque territorial proporcionando curules a los territorios afectados por el conflicto y toma en consideración los sectores poblacionales que por el ejercicio de la política y de liderazgos fueron perseguidos $\mathrm{y}$ asesinados. 


\section{BIBLIOGRAFÍA}

- BASSET, Yann. GUEVARA, Felipe. 2015. Voto preferente, democracia interna de las organizaciones políticas y aplicación de la cuota de género en un sistema electoral de lista cerrada. Bogotá, Colombia: Editor KAS paper.

- Barbosa, Francisco. La Corte Constitucional y el equilibrio de poderes. Ámbito jurídico.com

- Becerra, O.D. (Coord.(s), Estado y ciudadanía para la Paz (pp. 17-34). Bogotá: Universidad de Bogotá Jorge Tadeo Lozano.

- Carpizo, J. Concepto de democracia y sistema de gobierno en América Latina. Bogotá, Colombia: Universidad Externado de Colombia.

- Centro Internacional para la justicia transicional (2010) (Centro Internacional para la justicia transicional, 2010). Tareas pendientes: Propuestas para la formulación de políticas públicas de reparación en Colombia. Bogotá, Colombia: Opciones gráficas editores Ltda.

- Congreso de la República (junio de 2017) "Por medio del cual se crean 16 Circunscripciones Transitorias Especiales de Paz para la Cámara de Representantes en los periodos 2018 - 2022 y 2022 - 2026". (Proyecto de Acto Legislativo de 2017). Recuperado de http://www.mininterior.gov.co/sites/ default/files/noticias/acto_legislativo_ circuncripciones_27_03_2017.docx

- Congreso de la República (Julio 3 de 2003). "Por el cual se adopta una Reforma Política Constitucional y se dictan otras disposiciones". (Acto legislativo No. 01 de 2003). DO: 45237.

- Congreso de la República (Julio 22 de 2005). "Por el cual se modifica el artículo 176 de la Constitución Política". (Acto legislativo No. 2 de 2005). DO: 45980

- Congreso de la República (Diciembre 29 de 2005). "Por el cual se modifica el artículo 176 de la Constitución Política". (Acto legislativo No. 3 de 2005). DO: 46136

- Congreso de la República (julio 14 de
2009). "Por el cual se modifican y adicionan unos artículos de la Constitución Política de Colombia". (Acto legislativo No. 01 de 2009). DO: 47410

- Congreso de la República (julio 14 de 2011). "Por la cual se adoptan reglas de organización $\mathrm{y}$ funcionamiento de los partidos y movimientos políticos, de los procesos electorales y se dictan otras disposiciones". (Ley 1475 de 2011). Recuperado de http:// www.cne.gov.co/CNE/media/file/Ley\%20 1475\%20de\%202011.pdf

- Consejo de Estado, Sala de lo Contencioso Administrativo, Sección Quinta. (4 de julio de 2013) Radicación $\mathrm{N}^{\circ}$ : 11001-03-28000-2010-00027-00 (Consejera Ponente: Susana Buitrago Valencia)

- Consejo Nacional Electoral. (26 de noviembre de 2014).Resolución № 3594 de 2014 "Por medio de la cual se decide sobre la vigencia de la personería jurídica del partido político UNIÓN PATRIÒTICA".

- Consejo Nacional Electoral. (s.f.). Aclaración de voto, ASUNTO: Resolución No. 3594 del 26 de noviembre de 2014 Personería Jurídica de la Unión Patriótica. (M.P. Armando Novoa García)

- Corte Constitucional. (23 de agosto de 2016). Auto 373/16. (MP Luis Ernesto Vargas Silva).

- Corte Constitucional (13 de julio de 2016). Sentencia C-373. (MP Alejandro Linares Cantillo, Gabriel Eduardo Mendoza Martelo).

- Dangond Gibson, Claudia (2011). El Congreso en Colombia. En Lancheros J. C., Vargas J.C., (Coord.), 20 años de la Constitución Colombiana. Logros, retrocesos y agenda pendiente (pp. 347-354). Bogotà: Fundación Konrad Adenauer Stiftung -KAS -.

- Defensoría del Pueblo (30 de maro de 2017). Informe de Riesgo No. 01017-A.I.Bogotá D.C.

- Duque Daza, J. (s.f.). Redefinición de las reglas de juego, las lógicas del cambio institucional electoral. En Tarapúes 
Sandino, D.G.; Sánchez Espinoza, G. (Coord. (s)), Memorias IV Jornada de Derecho Público. Sistema electoral colombiano. Actualidad y perspectivas (pp.39-71). Cali, Valle del Cauca: Poemia.

- El Heraldo (23 de agosto de 2016) "Lo que debe conocer sobre las Circunscripciones Especiales de Paz". Recuperado de https:// www.elheraldo.co/politica/lo-que-debeconocer-sobre-las-circunscripcionesespeciales-de-paz-280019

- Fals Borda, O. (2000). El territorio colombiano no se dividirá. En Ortiz Nieves, J., La Paz. Análisis del proceso y propuestas para $\mathrm{u}$ nuevo sistema político en Colombia (pp. 220231).Bogotá, Colombia: Ediciones Aurora.

- Garay, L.J. (1999).Construcción de una nueva sociedad. Bogotá, Colombia: tercer mundo editores.

- González, Fernán. (Ed.) y otros. 2009. La violencia política en Colombia. De la nación fragmentada a la construcción del Estado. Bogotá, Colombia: Cinep.

- Hernández Becerra, Augusto (2009). Crisis de los partidos políticos y presidencialismo en Colombia. En Vanegas Gil, P.P. (Coord.), La democracia constitucional en América Latina y las evoluciones recientes del presidencialismo. Memorias Encuentro del Instituto Iberoamericano de Derecho Constitucional. Bogotá: Universidad Externado de Colombia.

- KAS (Enero de 2015). Papers No. 21. Reforma política 2015. El equilibrio de poderes y la definición de circunscripciones en Senado y Cámara. Bogotá, Colombia: Editor KAS Paper.

- Londoño, Juan Fernando. 2017. Hoja de ruta de las Reformas Políticas para la Paz. Bogotá. Colombia: Scripto editores, Netherlands Institute for Multiparty Democracy.

- López Díaz, C., González, D. Errandonea, J., (S.F.). En Forer, A., López Díaz, C., (Ed. (s), Colombia: un nuevo modelo de Justicia Transicional (pp. 11-115). Bogotá: GIZ.
- Medellín Torres, P. (2005). De la crisis de representación a la representación de la crisis en Colombia. Análisis de las alternativas de salida ofrecidas por el acto legislativo No. 01 de 2003 y la ley de bancadas de 2005. En Cárdenas Rivera M.E. (Coord.), La reforma política del Estado en Colombia -Una salida integral a la crisis - (pp.1948). Bogotà, Colombia: Fondo editorial CEREC.

- Ministerio del Interior (2012). 2 a Ed. Ley de víctimas y Restitución de Tierras y Decretos Reglamentarios "Por la cual se dictan medidas de atención, asistencia y reparación integral a las víctimas del conflicto armado interno y se dictan otras disposiciones". Bogotá, Colombia: Imprenta Nacional de Colombia.

- Misión Electoral Especial (abril de 2017). Reforma Política y electoral en Colombia. Propuestas. Bogotá, Colombia.

- Misión de Observación Electoral (junio de 2017). Circunscripciones Transitorias Especiales de Paz para la Cámara de Representantes 2018-2022 y 2022-2026. Bogotá, Colombia.

- Nohlen, D. (1994). Sistemas electorales y partidos políticos. México D.F.: Fondo de Cultura Económica.

- Notinetlegal (s.f.). "Análisis constitucional de la Jurisdicción Especial para la Paz en el marco del acto legislativo 01 de 2017" Recuperado de http://www.notinetlegal. com/anlisis-constitucional-de-lajurisdiccin-especial-de-paz-en-el-marcodel-acto-legislativo-no-1-de-20-209.html

- Ochoa, R. (2010). Honduras: en transición a la democracia. En Reed, M., River .M.C., Transiciones en contienda. Dilemas de la justicia transicional en Colombia y en la experiencia comparada (pp.376-399). Bogotá, Colombia: Opciones gráficas editores.

- Perdomo, C. (2014). Colombia. En Briscoe, I., Perdomo, C., Uribe Burcher, C., (Ed.(s). Redes ilícitas y política en América Latina (pp. 79-114). Bogotá: IDEA internacional, NIMD, Instituto Cliendegal.

- Puyana, J.R. (2012). Las reformas políticas 
en Colombia, 2003 - 2011 ¿hacia partidos más responsables? En Wills Otero, L., Batlle, M. (compiladoras), Política y territorio. Análisis de las elecciones subnacionales en Colombia, 2011 (pp. 17-62). Bogota, Colombia: Editorial Scripto S.A.S.

- Revista Semana (4 de abril de 2015) 25 años después de la muerte de Jaramillo y Pizarro. Hace un cuarto de siglo fueron asesinados los líderes: Bernardo Jaramillo y Carlos Pizarro. ¿Algún día gobernará la izquierda? Recuperado de http://www.semana.com/ nacion/articulo/25-anos-despues-de-lamuerte-de-jaramillo-pizarro/422884-3

- Revista Semana (6 de junio de 2017) La realidad de las Circunscripciones de Paz. Recuperado de http:// colombia2020.elespectador.com/pais/ la-realidad-de-las-circunscripciones-de-paz

- Revista Semana (29 de abril de 2017) "Hay que mejorar la representación territorial". Recuperado de http://www.semana.com/ enfoque/articulo/entrevista-hay-quemejorar-la-representacion-territorial/523715

- Roll D., Cruz, E. (2010). Un balance del sistema de financiamiento político en Colombia. En Roll, D., y Grupo de Investigación de Partidos Políticos de la Universidad Nacional de Colombia., ¿Democracias prepago? El control de la Financiación de la política, un reto para Colombia y Latinoamérica (pp. 21-48). Bogotá, Colombia: Digiprint Editores E.U.

- Roll D., Ballèn, L. (2010). Las dificultades del financiamiento de la política en Colombia y sus repercusiones en el sistema de partidos: algunas reflexiones sobre la "parapolítica". En Roll, D., y Grupo de Investigación de Partidos Políticos de la Universidad Nacional de Colombia., ¿Democracias prepago? El control de la Financiación de la política, un reto para Colombia y Latinoamérica (pp. 53-102). Bogotá, Colombia: Digiprint Editores E.U.

- Romero, M. (Ed.). (2007). Nuevas guerras, paramilitares e ilegalidad: una trampa difícil de superar. En parapolítica. La ruta de la expansión paramilitar y los acuerdos políticos (pp. 363-396). Bogotá, Colombia: Torre gráfica.

- Tarapués Sandino, D.F. (s.f.). A modo de introducción: fundamentos constitucionales del derecho electoral. En Tarapúes Sandino, D.G., Sánchez Espinoza, G. (Coord.), Memorias IV Jornada de Derecho Público. Sistema electoral colombiano. Actualidad y perspectivas (pp.1339). Cali, Valle del Cauca: Poemia.

- Tirado Mejía, A. 8 a Ed. Colombia: siglo y medio de bipartidismo (1982). En Colombia Hoy (pp.102-185). Bogotá, Colombia: Siglo XXI Editores.

- Valencia, L. (2007). Los caminos de la alianza entre los paramilitares y los políticos. En Archila L.A. (ed.), La ruta de la expansión paramilitar y los acuerdos políticos (pp. 1347). Bogotá, Colombia: Intermedio editores.

- Vanegas Gil, P.P. (2008). Estudios de derecho electoral. Bogotá, Colombia: Universidad Externado de Colombia.

- Vanegas Gil, P.P., (2009). Las candidaturas en el derecho electoral colombiano. Bogotá, Colombia: Universidad Externado de Colombia.

- VARGAS, Camilo. (2015). El equilibrio de poderes y la definición de circunscripciones en Senado y Cámara. Bogotá, Colombia: Editor KAS paper.

- Villar Jiménez, S. (2014). Código electoral. Normas constitucionales, legales y complementarias, reforma política, estatuto anticorrupción. 4 a Ed. Bogotá, Colombia: Jurídica Radar Ediciones.

- Universidad Externado de Colombia (Ed). 2009. Cátedra UNESCO. Derechos Humanos y violencia: gobierno y gobernanza. Las políticas públicas frente a las violaciones a los derechos humanos. Bogotá, Colombia.

- Walteros Rangel, D.A.(2011). Las concepciones de la construcción de paz: entre la estabilidad y la eficacia. En Ramírez Bonilla, L.C., Walteros Rangel, D.A., Andrade, O. Coord. Bogotá, Colombia: Universidad Jorge Tadeo Lozano. 